\title{
Effects of a Single Dose of Erythropoietin on Motor Function and Cognition after Focal Brain Ischemia in Adult Rats
}

\author{
Michaela Hralová ${ }^{1}$, Eva Plaňanská ${ }^{2}, Y_{v o n a}$ Angerová ${ }^{3}$, \\ Andrea Jadwiszczoková1, Jana Bortelová1, \\ Marcela Lippertová-Grünerová ${ }^{3,4}$, Dana Marešová ${ }^{1}$ \\ ${ }^{1}$ Institute of Physiology, First Faculty of Medicine, Charles University in Prague, \\ Prague, Czech Republic; \\ ${ }^{2}$ Department of Neurology, First Faculty of Medicine, Charles University \\ in Prague and General University Hospital in Prague, Prague, Czech Republic; \\ ${ }^{3}$ Department of Rehabilitation Medicine, First Faculty of Medicine, Charles \\ University in Prague and General University Hospital in Prague, Prague, \\ Czech Republic; \\ ${ }^{4}$ Faculty of Medicine, University of Cologne, Cologne, Germany \\ Received November 21, 2013; Accepted April 4, 2014.
}

Key words: Rats - Endothelin - Erythropoietin - Focal brain ischemia - Motor and cognitive function

\begin{abstract}
We tested the influence of erythropoietin (EPO), a basic cytokine in erythropoiesis regulation, on the process of motor function and cognition after focal brain ischemia induced by a local application of endothelin. Endothelin-1 (ET-1) induced short lasting strong vasoconstriction, with described impact on the structure and on the function of neuronal cells. Neurological description of motor function and Morris water maze test (the swimming test is one of most widely used methods for studying cognitive functions in rodents) were used to study the process of learning and memory in three-month-old male albino Wistar rats $(n=52)$. Both tests were performed one week before, and three weeks after ischemia induction (endothelin application on the cortex in the area of a.cerebri media dx.). Experimental group received i.p. injection of EPO $(5,000 \mathrm{lU} / \mathrm{kg}$ body weight, $10 \mathrm{~min}$ before endothelin application). Control group of animals received one i.p. injection of saline at the dose of $1 \mathrm{ml} / \mathrm{kg}$ body weight at the same time.
\end{abstract}

This study was supported by PRVOUK-P34/LF1/7.

Mailing Address: Assoc. Prof. Dana Marešová, MD., PhD., Institute of Physiology, First Faculty of Medicine, Charles University in Prague, Albertov 5, 12800 Prague 2, Czech Republic; Phone: +420 224968 410; e-mail: dana.maresova@|f1.cuni.cz 
Only sham surgery was performed in the third group of animals. Rats with EPO pretreatment before the experimental lesion exhibited significantly better motor and cognitive function then those with saline injection. No significant changes in the motor and cognitive function were found in the third group of rats (sham operated controls).

\section{Introduction}

Vascular brain disease is the third most frequent cause of death in humans after cancer and heart attack (Strong et al., 2007; Roger et al., 2012). Biochemical and pathophysiological consequences of the lesion lead to the damage and/or cell death. When the patients do not die, they are severely disabled (motor, e.g. hemiparesis, cognitive, e.g. defects in concentration and learning ability). This disability often requires lifelong care, which is physically, psychologically and economically very demanding. More-over the risk of disease recurrence is very high (Tateno et al., 2002; Visser-Keizer et al., 2002).

Functional changes occur within a period of hours to days (or even months) and provide a window of opportunity for therapeutic intervention with the potential to prevent or reduce damage and to improve long-term outcomes.

In animals, one of models of focal brain ischemia is the local application of endothelin-1 (ET-1). This peptide, a potent vasoconstrictor, is produced by vascular endothelial cells. ET-1 locally applied induces short-lasting vasoconstriction and blood flow diminution (cca $20 \mathrm{~min}$ ) with slow restoration of the blood flow (Sicard and Fischer, 2009).

\section{Erythropoietin (EPO)}

The naturally occurring cytokine erythropoietin (EPO) is widely known as a factor stimulating maturation, differentiation and survival of hematopoietic progenitor cells (Xiong et al., 2008). More-over EPO has been recently shown to be neuroprotective in the brain following a variety of injuries (cerebral ischemia, head injury, seizures, inflammation etc.) (Marti, 2004; Sargin et al., 2011).

Erythropoietin is a glycoprotein, whose molecule is formed by 164 amino acids and is strongly glycosylated - about $40 \%$ of its weight comprises carbohydrates joined to asparagine and serine. In humans, EPO is coded at the $7^{\text {th }}$ chromosome, which is exprimed in adults especially in peritubular interstitial fibroblasts in the kidneys (about $90 \%$ of EPO production) and perivenous hepatocytes in the liver (about 10\% of EPO production) (Lacombe and Mayeux, 1998; Semenza, 2001).

Biological effects of EPO are mediated by EPO receptors (EPOR), which are localized on the target cell's surface. Binding of EPO to its receptor induces dimerization of receptors subunits, activation of Janus kinase 2 (Janus-tyrosinkinasa 2, JAK 2) and signal transduction. Through this process, the active transcription factor STAT 5 (signal transducer and activator of transcription) is created. Its dimer penetrates into the cell nucleus and is able to bind to certain DNA 
sequences and influence the genes necessary for specific proteins synthesis and resultant cell differentiation (Jelkmann, 2004; Sola et al., 2005; Sargin et al., 2011).

Besides affecting red blood cells development, EPO also plays an important role in many other processes, such as multifunctional growth factor in the nervous system and heart. The erythropoietin receptors can be found on neurons, glial cells, endothelial cells and also on cardiomyocytes. Activated EPORs exert anti-apoptotic effects (as in erythropoiesis regulation), neuroregenerative and anti-inflammatory effects, and the stimulation of angiogenesis (Marti et al., 2000; Buemi et al., 2002; Marti, 2004; Sola et al., 2005; Paschos et al., 2008).

Therefore we hypothesized that EPO given to rats before the focal brain hypoxia were induced by endothelin-1 application, could influence the final outcome of their motor and cognitive functions.

\section{Material and Methods}

\section{Animals}

This study was performed in accordance with the Guide for Care and Use of Laboratory Animals of Central Commission for Animal Welfare (CCAW) of the Charles University in Prague. All efforts were used to minimize the animal discomfort and to reduce the total number of experimental animals.

Fifty-two male 3-month-old Wistar albino rats from our own breeding facility were used in this study. Animals were maintained in a temperature controlled room $\left(20-23{ }^{\circ} \mathrm{C}\right)$, on a $12 \mathrm{~h} \mathrm{light/dark}$ cycle, with commercial rat chow (Velas F1, Velas s.r.o., Lysá nad Labem, Czech Republic) and fresh water available ad libitum. The animals were tested between 14:00 and 16:00 h.

Model of experimental cerebral lesion

The experimental cerebral lesion was performed under general inhalation anesthesia, using isofluorane (Forane, inh. sol., isofluranum, Abbot Laboratories Ltd., Great Britain).

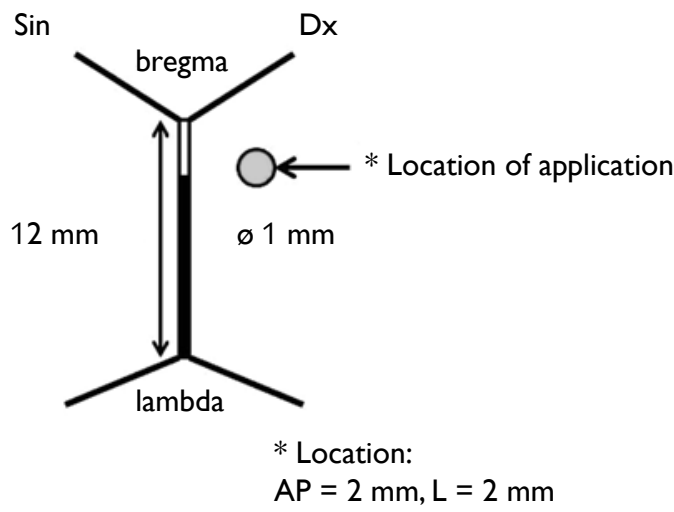

Focal Brain Ischemia and Erythropoietin
Figure 1 - Schema of craniotomy and location of drug application. 
The entire procedure lasted approximately 25 minutes.

The sedated animal was restrained within a stereotaxic frame, the skin was cleared, disinfected and a longitudinal cutaneous incision was made in the middle of the head (1.0-1.5 cm long). The skull was exposed and cranial sutures were used as landmarks for location of the drilling site (Figure 1). An electric drill was used to create a small (about $1.0 \mathrm{~mm}$ in diameter) hole in dexter part of the skull (AP $-2 \mathrm{~mm}, \mathrm{~L}-2 \mathrm{~mm}$ ). Dura mater covering the surface of the brain at the bottom of the craniotomy was gently removed. Through this opening in the skull, we applied the whole amount of endothelin-1 (ET-1) in $4.6 \mu \mathrm{l}$ of solution in special schedule, which allowed the solution to be completely absorbed by the brain tissue. After this part of surgery, we gently stitched the incision and terminated the anaesthesia. We removed the animal from the frame and placed it on a warm cover, where further observations were conducted.

\section{Drugs}

Experimental animals were randomly divided in three groups. First experimental group $(n=15)$ was administered by intraperitoneal (i.p.) injection of EPO (NeoRecormon - Epoetinum beta, Roche, 5,000 IU/ml, Great Britain) at a dose of $5,000 \mathrm{IU} / \mathrm{kg}$ body weight 10 minutes before the endothelin-1 application. Instead of EPO, the second - control group $(n=21)$ received one i.p. injection of pure saline (Natrium Chloratum, sol. isotonica, Hoechst-Biotika, Germany) in the same time. In third group $(n=16)$ only sham surgery was utilized.

\section{Testing of motor functions}

In this observation spontaneous motor activity (behavior of freely moving animals) and provoked motor activity (for example beam balance, beam walking, rotary wheel etc.) were evaluated, as well as changes in behavior and eating habits. Maximum number of points in this testing was is 288 . This Neuroscore was made according to Neuroscore 100 in rats (Thal et al., 2008).

Morris water maze (MWM) - Testing of cognitive functions

This maze was developed by Richard Morris and described by him in the early 1980 s for neurobehavioral studies involving the testing of the spatial memory and learning ability in animals: the animal is placed into a circular pool of water and it is required to escape from the water on a small platform that is hidden under the water's surface. Improved performance in finding of the target is possible due to learning and spatial memory of the rat. The learning ability is evaluated mainly in two aspects - escape latency (in seconds) and path length (in meters). The movements of rats were recorded by a video camera connected to a computer running the program ANY MAZE (ANY MAZE, Stoelting Co., USA) (Klement et al., 2008; Hralová et al., 2011). 
Timeline of experimental procedures

The whole study took 33 days to complete. The assessment was divided into two parts.

\section{Part l. Motor function assessment}

In this part was provided the evaluation of motor function in rats. Motor function assessments were made on days 8 (two days before experimental focal ischemia), 11 (acute effect), 15, 22 and 29 (long-term effects) of the study. These dates correspond to the $1^{\text {st }}, 5^{\text {th }}, 12^{\text {th }}$, and $19^{\text {th }}$ day following the experimentally induced focal brain ischemia (Figure 2).

\section{Part II. Cognitive function assessment}

Cognitive functions were assessed using a Morris water maze. The rats were given three training periods. Each period consisted of five consecutive days, of eight trials per day, in the MWM.

The first training period started the first day of the study (before the focal brain ischemia), the second period occurred from days 15 to $19\left(5^{\text {th }}-9^{\text {th }}\right.$ day following the ischemia), the final period was led from days 29 to $33\left(19^{\text {th }}-23^{\text {rd }}\right.$ day following the ischemia) (Figure 2).

\section{Hematocrit}

As a control measurement of erythrocyte concentration we measured hematocrit from the venous tail blood in all rats groups.

\section{Statistics}

A Shapiro-Wilk test revealed that our data deviate from the assumption of normality and thus the nonparametric Mann-Whitney rank-sum test was used to compare experimental and control groups. The Mann-Whitney test compares ranks

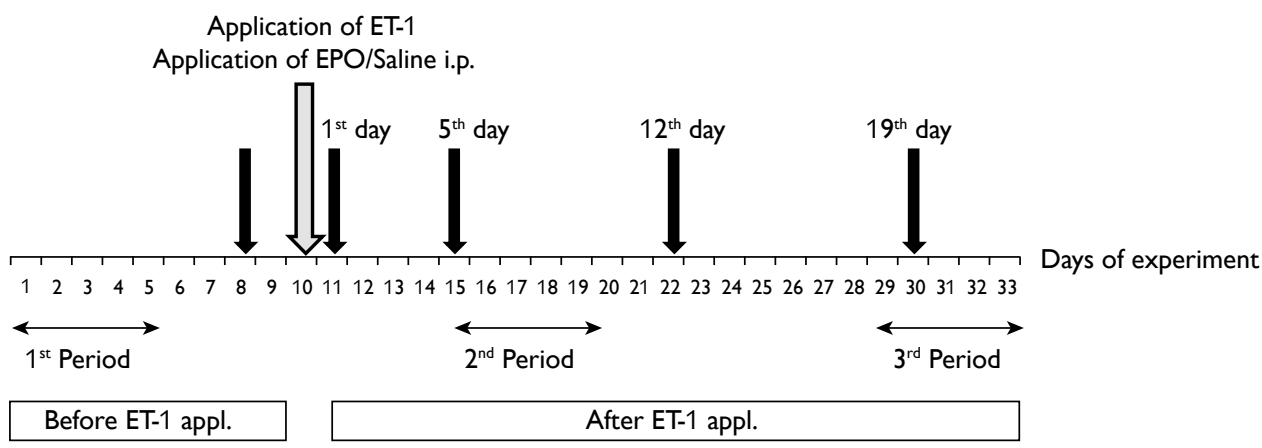

Figure 2 - Timeline of experimental procedures. 
rather than mean values and is the nonparametric alternative to the $t$ test for two independent groups. Statistical significance was set at $p<0.05$.

\section{Results}

\section{Part l. Motor function assessment}

Motor functions that were assessed included (spontaneous motor activity, provoked motor activity, and changes in behavior and eating).

The rats treated with EPO eventually exhibited better motor outcomes, but not until after the $1^{\text {st }}$ day after a focal ischemia (acute effect of EPO). Analyses of the long-term effects $\left(5^{\text {th }}, 12^{\text {th }}\right.$ and $19^{\text {th }}$ day following ischemia) shoved that rats treated with EPO had significantly higher behavioral scores than rats that received only saline ( $p<0.05$ or 0.01 , Figure 3$)$.

\section{Part II. Cognitive function assessment}

\section{Escape latency}

The significant differences between both groups - in rats treated EPO and in rats administrated only by saline, were revealed ( $p<0.05$ for all test days, $p<0.01$ or 0.001 in most cases). The rats treated with EPO found the target much faster and remembered position of hidden island statistically significantly better (even better than before experimental ischemia) than the rats administrated only by saline (Figure 4).

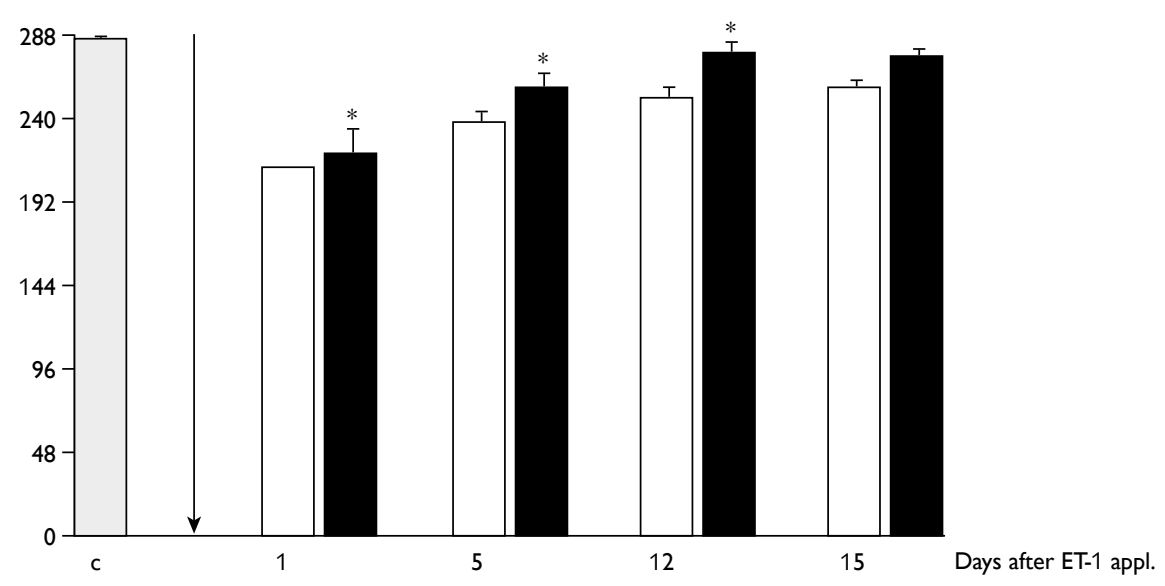

Figure 3 - Motor functions - general evaluation.

Gray column (C) - animals before ET-1 application; white columns - animals treated with saline; black columns animals treated with EPO; arrow - day of ET-1 application; X-axis - days after ET-1 application; Y-axis - number of points (maximal number of points reached by each animal when summarized; total number of points is 288); $* p<0.05$ 


\section{Path length}

The significant differences between both groups - in rats treated EPO and in rats administrated only by saline, were very similar as the evaluation of escape latency. The path length was statistical significantly shorter (better than before focal ischemia) in the rats treated by EPO then in the rats administrated only by saline. The rats injected only by saline were in latencies in all monitored days worth even in comparison with time before ischemia.

No statistical changes were registered in the group only with sham surgery in correlation with results before ET-1 application and after ET-1 application both $E P O$ and saline injection.

\section{Hematocrit}

The rats treated with EPO possessed significant higher level of hematocrit only on the $1^{\text {st }}$ and $5^{\text {th }}$ day after focal ischemia. During later periods, however, there were
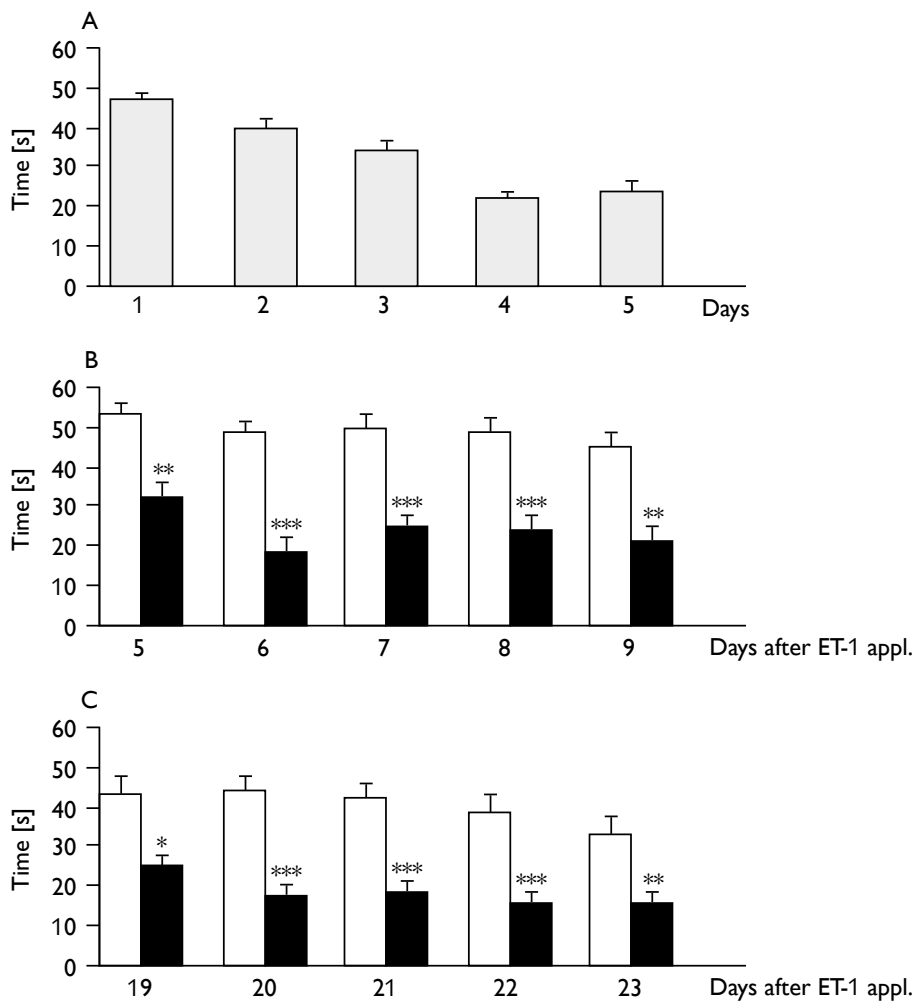

Figure 4 - Cognitive functions - escape latency. Figure 4A - First period (before ET-1 application). Figure 4B - Second period (after ET-1 application). Figure 4C - Third period (after ET-1 application). Gray columns - animals before ET-1 application; white columns - animals treated with saline; black columns - animals treated with EPO; X-axis - days of experiment; Y-axis - escape latency; ${ }^{*} p<0.05 ; * * p<0.01$; $* * * p<0.001$ 
no differences between hematocrit level between experimental and control groups. More-over, all hematocrit measures were within normal physiological ranges $(\mathrm{HTC}=0.54-0.63)$.

\section{Discussion}

Vascular brain disease, mainly stroke, is a very serious disease, which causes different morphological and functional changes in the brain. Treatment of surviving human patients is very complicated and demanding. The lifelong care of those severely sick and disabled patients is physically, psychologically and economically very difficult and demanding. More over the risk of disease recurrence is very high (Sveen et al., 2003; Murphy et al., 2004). Long-term prognoses are often poor (especially in terms of cognitive functions) in spite of using different neuro-rehabilitation methods (Lippert-Grüner et al., 2007; Fitzgerald et al., 2010).

No measures for targeted neuroprotection currently exist. Studies seeking a neuroprotective agent have tested a variety of pharmacological agents (e.g. amphetamine, dopamine) but these have been ruled out, partly due to severe side effects. The only current method for stimulating cerebral reorganization and plasticity entails neurorehabilitation involving repetitive magnetic stimulation of motor cortex in association with mental training. However, the results of such neurorehabilitation are limited, and many patients retain motor and cognitive handicaps (Gauggel et al., 2000; Morrison et al., 2005).

The purpose of the present study was to evaluate the potential of a novel neuroprotective and neuroreparatory methodology for stroke therapy. The stroke condition was experimentally induced via application of ET-1 in the area a. cerebri med. $\mathrm{dx}$. of the brain cortex - a methods that closely mimics the pathology of stroke in humans, more-over very similar are morphological changes in brain tissue as well (Mareš, 1995; Fuxe et al., 1997).

EPO administration was chosen for the experimental treatment due to evidence of its neuroprotective, neuroregenerative and antiinflammatory effects (Marti, 2004; Xiong et al., 2008; Osredkar et al., 2010; Cherian et al., 2011).

Our results support a notion of EPO as neuroprotective since a single EPO dose enhanced both motor and cognitive functioning in rats after experimental focal brain ischemia, relative to control subjects that were administrated only saline. General behavioral activity levels were also higher in the EPO-treated rats than in control subjects.

Here we would like to emphasize that the neuroprotective actions of EPO require the presence of its cognate receptor. Erythropoietin receptors have indeed been found in the brain of numerous mammals including humans (Digicaylioglu et al., 1995).

EPO (induced by hypoxia) is considered to have a key role in the enhancement of brain robustness to hypoxia (Sharp and Bernaudin, 2004). Human recombinant 
EPO ( $r-H u-E P O)$ could be considered as enviro-mimetic, defined as any exogenous molecule that mimics the beneficial effects of environmental changes (Nithianantharajan and Hannan, 2006). There is a concept that the optimization of the effect of a neuroprotective agent may require the preliminary induction of its targeted receptor (Lipton, 2007).

EPO acts in the CNS primarily as a direct protective factor in neurons via the activation of anti-apoptotic pathways. Of course, this effect on neurons could be supported by their direct actions of EPO and other growth factors on endothelial cells, thereby resulting in cell survival and stimulation of new blood vessel growth as well as on glial cells leading to modulation of pathological responses (Marti, 2004).

A milestone in the history of biological activities of EPO was the paper of Brines et al. (2000) who demonstrated that cross-talk between peripheral and central EPO systems is possible, mainly in injured tissue, where the blood brain barrier (BBB) is breached.

At that time, it was not known how EPO mediates its effects across the BBB, but the observations were consistent with the specific receptor-mediated translocation of EPO into the brain (Brines et al., 2000, 2004; Brines and Cerami, 2008).

Presents of EPO and EPO receptors (EPOR) in the central nervous system and cerebrospinal fluid was discovered only later, explaining the hypoxia/ischemia responsive production of EPO acts as neurotropic and neuroprotective factor (Buemi et al., 2002).

Recent researches show, that in brain tissue, EPO is highly expressed in astrocytes while neurons express EPOR. After brain injury EPO acts via a non-hematopoietic protective pathway, via regulation of neurotropic factors with antiapoptotic, antiinflammatory, and angiogenetic properties (Hartley et al., 2008; Mammis et al., 2009; Xu et al., 2012).

Results of our research support the hypothesis that EPO can influence the long-term impairment of motor and cognitive functions, as well as the general behavior, in rats experimentally exposed to focal ischemia. More-over, since long-term hematocrit levels were normal, we can conclude that the EPO-induced benefits are not due to higher levels of circulating erythrocytes and accompanying partial pressures of oxygen at target tissues, but represent the direct neuroprotective effects of EPO.

In conclusion we can pronounce that the application of erythropoietin has positive effects on motor and cognitive function in adult rats exposed to focal brain ischemia by endothelin-1 application at the area of a. carotis media $\mathrm{dx}$.

Acknowledgements: The authors thank to Ing. Alena Dohnalová (Institute of Physiology, First Faculty of Medicine, Charles University in Prague, Prague, Czech Republic) for her valuable advice and help with statistical analyses of the outcomes in this study. 


\section{References}

Brines, M. L., Cerami, A. (2008) Erythropoietin-mediated tissue protection: reducing collateral damage from the primary injury response. J. Intern. Med. 264, 405-432.

Brines, M. L., Ghezzi, P., Keenan, S., Agnello, D., de Lenarolle, N. C., Cerami, C., Itri, L. M., Cerami, A. (2000) Erythropoietin crosses the blood-brain barrier to protect against experimental brain injury. Proc. Natl. Acad. Sci USA 97, 10526-10531.

Brines, M. L., Grasso, G., Fiordaliso, F., Sfacteria, A., Ghezzi, P., Fratelli, M., Latini, R., Xie, Q.W., Smart, J., Su-Rick, C. J., Pobre, E., Diaz, D., Gomez, D., Hand, C., Coleman, T., Cerami, A. (2004) Erythropoietin mediates tissue protection through an erythropoietin and common $\beta$-subunit heteroreceptor. Proc. Natl. Acad. Sci. USA 101, 14907-14912.

Buemi, M., Cavalero, E., Floccari, F., Sturiale, A., Aloisi, C., Trimarchi, M., Grasso, G., Corica, F., Frisina, N. (2002) Erythropoietin and the brain: from neurodevelopment to neuroprotection. Clin. Sci. (Lond.) 103, $275-282$.

Cherian, L., Goodmann, J. C., Robertson, C. (2011) Improved cerebrovascular function and reduced histological damage with darbepoetin alfa administration after cortical impact injury in rats. J. Pharmacol. Exp. Ther. 337, 451-456.

Digicaylioglu, M., Bichet, S., Marti, H. H., Wenger, R. H., Rivas, L. A., Bauer, C., Gassmann, N. M. (1995) Localization of specific erythropoietin binding sites in defined areas of the mouse brain. Proc. Natl. Acad. Sci. USA 92, 3717-3720.

Fitzgerald, A., Aditya, H., Prior, A., McNeill, S., Pentland, B. (2010) Anoxic brain injury: Clinical patterns and functional outcomes. A study of 93 cases. Brain Inj. 24, 1311-1323.

Fuxe, K., Bjelke, B., Andbjer, B., Grahn, H., Rimondini, R., Agnati, L. F. (1997) Endothelin-1 induced lesions of the frontoparietal cortex of the rat. A possible model of focal cortical ischemia. Neuroreport $\mathbf{8}$, 2623-2629.

Gauggel, S., Peleska, S., Bode, P. (2000) Relationship between cognitive impairments and rated activity restrictions in stroke patients. J. Head Trauma Rehabil. 15, 710-723.

Hartley, C. E., Vaema, M., Fischer, J. P., Riccardi, R., Strauss, J. A., Shah, S., Zhang, S., Yang, Z. J. (2008) Neuroprotective effects of erythropoietin on acute metabolic and pathological changes in experimentally induced neurotrauma. J. Neurosurg. 109, 708-714.

Hralová, M., Marešová, D., Riljak, V. (2011) Is learning ability and spatial memory in rats influenced by single dose of nicotine? Prague Med. Rep. 112, 193-204.

Jelkmann,W. (2004) Molecular biology and erythropoietin. Intern. Med. 43, 649-659.

Klement, D., Blahna, K., Nekovářová, T. (2008) Novel behavioral tasks for studying spatial cognition in rats. Physiol. Res. 57, S161-S165.

Lacombe, C., Mayeux, P. (1998) Biology of erythropoietin. Haematologica 83, 724-732.

Lippert-Grüner, M., Maegele, M., Pokorný, J., Angelov, D. N., Švestková, O., Wittner, M., Trojan, S. (2007) Early rehabilitation model shows positive effect on neural degeneration and recovery from neuromotor deficits following traumatic brain injury. Physiol. Res. 56, 359-368.

Lipton, S. A. (2007) Pathologically activated therapeutics for neuroprotection. Nat. Rev. Neurosci. 8, 803-808.

Mammis, A., Mclntosh, T. K., Maniker, A. H. (2009) Erythropoietin as a neuroprotective agent in traumatic brain injury: Review. Surg. Neurol. 71, 527-531.

Mareš, J. (1995) Některé modely fokální hypoxie CNS. Čs. Fyziol. 44, 183-187.

Marti, H. H. (2004) Erythropoietin and the hypoxic brain. J. Exp. Biol. 207, 3233-3242.

Marti, H. H., Bernardin, M., Petit, E., Bauer, C. (2000) Neuroprotection and angiogenesis: Dual role of erythropoietin in brain ischemia. News Physiol. Sci. 15, 225-229.

Morrison, V., Pollard, B., Johnston, M., MacWalter, R. (2005) Anxiety and depression 3 years following stroke: demographic, clinical and psychological predictors. J. Psychosom. Res. 59, 209-213.

Hralová M. et al. 
Murphy, J. M., Horton, N. J., Laird, N. M., Monson, R., Sobol, A., Leighton, A. (2004) Anxiety and depression: a 40-year perspective on relationships regarding prevalence, distribution and comorbidity. Acta Psychiatr. Scand. 109, 355-375.

Nithianantharajan, J., Hannan, A. J. (2006) Enriched environments, experience-dependent plasticity and disorders of the nervous system. Nat. Rev. Neurosci. 7, 697-709.

Osredkar, D., Sall, J.W., Bickler, P. E., Ferriero, D. M. (2010) Erythropoietin promotes hippocampal neurogenesis in in vitro models of neonatal stroke. Neurobiol. Dis. 38, 259-265.

Paschos, N., Lykissas, M. G., Beris, A. E. (2008) The role of erythropoietin as an inhibitor of tissue ischemia. Int. J. Biol. Sci. 4, 161-168.

Roger, V. L., Go, A. S., Lloyd-Jones, D. M., Benjamin, E. J., Berry, J. D., Borden, W. B., Bravata, D. M., Dai, S., Ford, E. S., Fox, C. S., Fullerton, H. J., Gillespie, C., Hailpern, S. M., Heit, J. A., Howard, V. J., Kissela, B. M., Kittner, S. J., Lackland, D. T., Lichtman, J. H., Lisabeth, L. D., Makuc, D. M., Marcus, G. M., Marelli, A., Matchar, D. B., Moy, C. S., Mozaffarian, D., Mussolino, M. E., Nichol, G., Paynter, N. P., Soliman, E. Z., Sorlie, P. D., Sotoodehnia, N., Turan, T. N., Virani, S. S., Wong, N. D., Woo, D., Turner, M. B. (2012) Heart disease and stroke statistics - 2012 update: a report from the American Heart Association. Circulation 125, e2-e220.

Sargin, D., El-Kordi, A., Agarwal, A., Müller, M., Wojcik, S. M., Hassouna, I., Sperling, S., Nave, K. A., Ehrenreich, $\mathrm{H}$. (2011) Expression of constitutively active erythropietin receptor in pyramidal neurons of cortex and hippocampus boots higher cognitive functions in mice. BMC Biol. 9, 27.

Semenza, G. L. (2001) HIF-1 and mechanisms of hypoxia sensing. Curr. Opin. Cell Biol. 13, 167-171.

Sharp, F. R., Bernaudin, M. (2004) HIF1 and oxygen sensing in the brain. Nat. Rev. Neurosci. 5, 437-448.

Sicard, K., Fischer, M. (2009) Animal models of focal brain ischemia. Exp. Transl. Stroke Med. 13, 1-7.

Sola, A., Rogido, M., Lee, B. H., Genetta, T., Wen, T. C. (2005) Erythropoietin after focal cerebral ischemia activates the Janus kinase-signal transducer and activator of transcription signaling pathway and improves brain injury in postnatal day 7 rats. Pediatr. Res. 57, 481-487.

Strong, K., Mathers, C., Bonita, R. (2007) Preventing stroke: saving lives around the word. Lancet Neurol. 6, 182-187.

Sveen, U., Bautz-Holter, E., Soedring, K. M., Wyller, T. B., Laake, K. (2003) Association between impairments, self-care ability and social activities 1 year after stroke. Disabil. Rehabil. 21, 372-377.

Tateno, A., Murata, Y., Robinson, R. (2002) Comparison of cognitive impairment associated with major depression following stroke versus traumatic brain injury. Psychosomatics 43, 295-301.

Thal, S. C., Mebmer, K., Schmidt-Elsaesser, R., Zausinger, S. (2008) Neurological impairment in rats after subarachnoid hemorrhage - a comparison of functional tests. J. Neurol. Sci. 268, 150-159.

Visser-Keizer, A. C., Meyboom-de Jong, B., Deelman, B. G., Berg, I. J., Gerritsen, M. J. J. (2002) Subjective changes in emotion, cognition and behaviour after stroke: factors affecting the perception of patients and partners. J. Clin. Exp. Neuropsychol. 24, 1032-1045.

Xiong, Y., Lu, D., Qu, C., Goussev, A., Schallert, T., Mahmood, A., Chopp, M. (2008) Effects of erythropoietin on reducing brain damage and improving functional outcome after traumatic brain injury in mice. J. Neurosurg. 109, 510-521.

Xu, F., Yu, Z. Y., Gind, L., Zheng, S. Y. (2012) Experimental studies of erythropoietin protection following traumatic brain injury in rats. Exp. Ther. Med. 4, 977-982. 